\title{
Two cases of food-borne botulism in Finland caused by conserved olives, October 2011
}

K Jalava (katri.jalava@thl.fi) ${ }^{1}$, K Selby ${ }^{2}$, A Pihlajasaari³ ${ }^{3}$ E Kolho ${ }^{4}$, E Dahlsten² ${ }^{2}$, N Forss ${ }^{4}$, T Bäcklund ${ }^{4}$, H Korkeala ${ }^{2}$, T Honkanen-

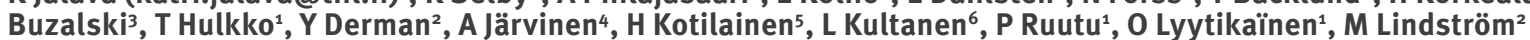

1. Department of Infectious Disease Surveillance and Control, National Institute for Health and Welfare, Helsinki, Finland

2. Department of Food Hygiene and Environmental Health, Faculty of Veterinary Medicine, University of Helsinki, Finland

3. Finnish Food Safety Authority Evira, Helsinki, Finland

4. Department of Medicine, Helsinki University Central Hospital, Helsinki, Finland

5. City of Helsinki Health Centre, City Hospital, Epidemiology Unit, Finland

6. City of Helsinki Environment Centre, Environmental Health Unit, Finland

Jalava K, Selby K, Pihlajasaari A, Kolho E, Dahlsten E, Forss N, Bäcklund T, Korkeala H, Honkanen-Buzalski T, Hulkko T, Derman Y, Järvinen A, Kotilainen H, Kultanen L, Ruutu P, Lyytikaïnen O, Lindström M. Two cases of food-borne botulism in Finland caused by conserved olives, October 2011.

Euro Surveill. 2011;16(49):pii=20034. Available online: http://www.eurosurveillance.org/ViewArticle.aspx?Articleld=20034

Article published on 8 December 2011

In October 2011 in Finland, two persons fell ill with symptoms compatible with botulism after having eaten conserved olives stuffed with almonds. One of these two died. Clostridium botulinum type B and its neurotoxin were detected in the implicated olives by PCR and mouse bioassay, respectively. The olives were traced back to an Italian manufacturer and withdrawn from the market. The public and other European countries were informed through media and Europewide notifications.

We describe two cases of food-borne botulism linked to consumption of conserved olives, identified in Finland in October 2011.

\section{Description of cases}

In mid-October 2011, the National Institute for Health and Welfare (THL) in Finland was informed of a suspected case of food-borne botulism. This was an elderly person who had been admitted to the Helsinki University Central Hospital three days earlier due to acute onset of dizziness, blurred vision, dysphagia and dysarthria but not preceded by gastrointestinal symptoms. One day after hospital admission, the patient's condition deteriorated and food-borne botulism was suspected based on clinical symptoms a day later. The suspected case had no history of travel, and wound botulism was ruled out because of intact skin. During days 1 and 2 of hospitalisation, descending paralysis progressed rapidly to nearly total tetraparesis and respiratory muscle failure requiring mechanical ventilation. Clinical presentation and no abnormalities in the cerebrospinal fluid were suggestive of botulism. Electroneuromyography (ENMG) did not definitely distinguish botulism from other neuromuscular diseases. The index case developed multi-organ failure and died in hospital 14 days after admission.
Four days after the index case was hospitalised, a young adult person in the same household also presented with impaired (double) vision, dysphagia and dysarthria. During interviews with the two cases and two other household members, it was found that both cases had eaten conserved olives stuffed with almonds from a previously unopened glass jar in mid-October at an interval of three days between each other. As this food item was the most plausible vehicle, it was tested before any other food item collected from the household. Of the two other household members, one had diarrhoea but none had any neurological symptoms. One of these two persons had tasted the implicated olives while the other had not eaten any.

\section{Laboratory investigation}

Serum, gastric content and faecal samples were taken from both suspected cases and sent to the Department of Food Hygiene and Environmental Health, Faculty of Veterinary Medicine, University of Helsinki for analysis of botulinum neurotoxin and Clostridium botulinum. The index case was sampled three days after the onset of symptoms, and samples from the second case were taken on the day of hospital admission, after the administration of a trivalent antitoxin. The serum and gastric content samples were tested in the standard mouse bioassay [1] and the gastric content and faecal samples were also tested with multiplex-PCR $[2,3]$. Various food samples (of 20 food items among which sun dried tomatoes, black olives, various fish products) obtained from the household refrigerator were tested by PCR, and the jar of olives from which the two cases had eaten the olives was also subjected to the mouse bioassay.

The serum sample of the index case showed a weak positive result in the mouse assay, suggesting the presence of borderline amount of botulinum neurotoxin 
in the patient's serum. However, all the other clinical samples from both patients were negative for the neurotoxin. Botulinum neurotoxin type $B$ gene was detected in the gastric content and faecal samples from both patients and in the implicated jar of olives, indicating the presence of $C$. botulinum type B organisms in these samples. The olives were strongly positive for botulinum neurotoxin type B. A PCR typing assay [4] showed the olive isolate to be $f l d B$ positive, suggesting the isolate to be proteolytic and thus belong to $C$. botulinum Group I.

\section{Product trace-back investigation}

The pasteurised olives stuffed with almonds had been manufactured and packed in Italy. A consignment of 900 glass jars of $314 \mathrm{ml}$ had been imported to Finland in 2010. Two different batches were identified, labelled with best before dates of August 2012 and September 2012, respectively. They had been sold in three supermarkets in three cities, two in the metropolitan area (Espoo and Vantaa) and one in northern Finland (Rovaniemi), and in five restaurants in central Helsinki and Vantaa. The olives had also been delivered by the restaurants to clients and business associates. The two cases described above had received the olives as a gift. All the products that were still in store were withdrawn by the local authorities and importing company one day after notification. Rapid Alert System for Food and Feed (RASFF) and Early Warning and Response System (EWRS) notifications were issued on 21 October 2011. The restaurants helped in identifying clients to whom they had delivered olives. The supermarket chain used its records of loyalty cards to identify customers who had purchased olives. The jar found at the home of the cases was from the batch with expiry date September 2012. It was noted that some of the glass jars of both olive batches were leaking. By visual inspection it was established that the content in some of the leaking jars was spoiled. However, laboratory investigations did not reveal botulinum neurotoxin or C. botulinum in these jars. The Italian RASFF authorities identified that the product had been exported to at least the following countries in the European Union (EU): the Czech Republic, France, Germany, Ireland, the Netherlands, Spain and the United Kingdom as well as to some non-EU countries: Armenia, Barbados, Brazil, Japan, Russia, Saudi Arabia, Switzerland, Taiwan and the United States of America. No human cases of botulism associated with this batch of olives have been reported to date through the EWRS from other EU or non-EU countries.

\section{Media coverage}

The general public was informed about these cases by a joint press release of THL, Finnish Food Safety Authority Evira, University of Helsinki and the City of Helsinki on 21 October 2011. The product was identified in the press release by a photo of a jar of olives from the implicated batch and advice was given to seek urgent medical attention in case of symptoms (gastrointestinal symptoms or difficulties in speaking and swallowing or visual impairment) after consumption of suspected olives. Following the press release, there was an information exchange between various European and international health organisations such as the European Centre for Disease Prevention and Control, the World Health Organization Regional Office for Europe and the United States' Centers for Disease Control and Prevention. The incident gained wide coverage in the Finnish media over the weekend of 22 and 23 October and again one week later after the death of the first case.

\section{Discussion and conclusion}

Food-borne botulism remains a serious threat and may be caused by products distributed internationally. In Finland, food-borne botulism is rare and most domestic cases have been associated with fish products caused by $C$. botulinum type $E$ toxin $[5,6]$. In 2009, two cases of food-borne botulism were detected among French tourists who purchased fish from Finland which was stored inappropriately and consumed after having returned home [7]. In 2006, two persons in Finland were diagnosed with food-borne botulism after having eaten vacuum-packed smoked whitefish [8]. Previously in Italy, conserved olives have also been implicated as a vehicle for food-borne botulism [9].

The immediate concern in respect to the incident described here is that jars of olives of the implicated batch may still be present in households in different countries. The assumption of severe failure in the processing, packaging and transportation of the implicated product is supported by the fact that several jars had cap leakage and the content was spoiled. The jar from which the two cases ate olives had been unopened prior to consumption and the product was within the given shelf life. However, as no other cases have been reported, it appears that only a single jar supported $C$. botulinum growth and botulinum neurotoxin production. It may also be that spoilage bacteria, as detected in some of the other jars, inhibited the growth of $C$. botulinum. The response to the cases described above was timely. However, continuous vigilance of clinicians for suspected cases of food-borne botulism is needed.

\section{References}

1. Nordic Committee on Food Analysis. Botulinum toxin. Detection in foods, blood and other test materials. Nordic Committee on Food Analysis; 1991; Method no. 79, 2nd ed.

2. Lindström M, Keto R, Markkula A, Nevas M, Hielm S, Korkeala H. Multiplex PCR assay for detection and identification of Clostridium botulinum types $A, B, E$, and $F$ in food and fecal material. Appl Environ Microbiol. 2001;67(12):5694-9.

3. De Medici D, Anniballi F, Wyatt GM, Lindström M, Messelhäusser U, Aldus CF, et al. Multiplex PCR for detection of botulinum neurotoxin-producing clostridia in clinical, food, and environmental samples. Appl Environ Microbiol. 2009;75(20):6457-61.

4. Dahlsten E, Korkeala H, Somervuo P, Lindström M. PCR assay for differentiating between Group I (proteolytic) and Group II (nonproteolytic) strains of Clostridium botulinum. Int J Food Microbiol. 2008;124(1):108-11.

5. Lindström M, Korkeala H. Laboratory diagnostics of botulism. Clin Microbiol Rev. 2006;19(2):298-314. 
6. Lindström M, Kiviniemi K, Korkeala H. Hazard and control of group II (non-proteolytic) Clostridium botulinum in modern food processing. Int J Food Microbiol. 2006;108(1):92-104.

7. King LA, Niskanen T, Junnikkala M, Moilanen E, Lindström M, Korkeala $\mathrm{H}$, et al. Botulism and hot-smoked whitefish: a family cluster of type E botulism in France, September 2009. Euro Surveill. 2009;14(45):pii=19394. Available from: http://www. eurosurveillance.org/ViewArticle.aspx?Articleld=19394

8. Lindström M, Vuorela M, Hinderink K, Korkeala H, Dahlsten $E$, Raahenmaa $M$, et al. Botulism associated with vacuumpacked smoked whitefish in Finland, June-July 2006. Euro Surveill. 2006;11(29):pii=3004. Available from: http://www. eurosurveillance.org/ViewArticle.aspx?Articleid=3004

9. Cawthorne A, Celentano LP, D’Ancona F, Bella A, Massari M, Anniballi F, et al. Botulism and preserved green olives. Emerg Infect Dis. 2005;11(5):781-2. 